\title{
TÉCNICAS DE IMAGEN EN EL REFLUJO VESICOURETERAL
}

\author{
Ignacio Alonso Usabiaga, Cristina Bravo Bravo, Pascual García-Herrera Taillefer, Esperanza Valls \\ Moreno y María Luisa Ceres Ruíz.
}

Sección de Radiología Pediátrica. Hospital Materno Infantil Carlos Haya. Málaga. España.

Resumen.- OBJETIVO: A pesar de que el RVU es una patología muy frecuente en la edad pediátrica y desde hace años ocupa gran parte de la actividad de pediatras, urólogos, nefrólogos y radiólogos pediátricos, sigue siendo controvertido su manejo global tanto en los aspectos diagnósticos como de tratamiento. El objetivo de este trabajo es hacer una puesta al día en la utilización de las diferentes técnicas de imagen en el diagnóstico y seguimiento del RVU y proponer un protocolo de estudio.

MÉTODOS: Se describen las diferentes técnicas de imagen: CUMS, Ecografía, Urografía intravenosa, Cistosonografía, Cistografía Isotópica, DMSA, Resonancia Magnética y su papel actual en la valoración y seguimiento del RVU. Se hace una revisión de la literatura sobre este tema y aportamos la experiencia de nuestro grupo de trabajo en el RVU.

RESULTADOS: La revisión de la literatura pone de manifiesto una clara evolución en los conceptos del RVU y también en los algoritmos de manejo del mismo. El concepto de lesión renal congénita sin infección del tracto urinario (ITU) o lesión adquirida después de una ITU está ya claramente diferenciado en las revisiones mas recientes. El reflujo está pasando de ser el centro del problema a ser un fenómeno secundario en relación a la ITU lo que está llevando a un cambio en la estrategia diagnóstica, cada vez menos invasiva.

CONCLUSIONES: La CUMS ha sido hasta ahora la primera e "indiscutible" técnica en el manejo del RVU, sobre todo en la fase diagnóstica, pero los avances tecnológicos en el área de los ultrasonidos (contrastes ecográficos, imagen armónica, etc) han hecho que la ecografía se haya convertido en la principal técnica de imagen en el manejo del RVU en la edad pediátrica. Por otro lado, los algoritmos de estudio del RVU han cambiado por el gran impacto que el diagnóstico prenatal está teniendo en el manejo de las anomalías del aparato urinario.

Palabras clave: Infección de orina. Diagnóstico prenatal. Dilatación renal fetal. CUMS. Cistosonografía. Ecografía renal. Reflujo vesicoureteral.

Summary.- OBJECTIVES: Although vesicoureteral reflux (VUR) is a very frequent pathology in the pediatric age and represents an important part of the activity of pediatricians, pediatric urologists, nephrologists, and radiologists, yet there is controversy about its global management both in diagnosis and treatment. The objective of this paper is to perform an update in the use of different imaging techniques in the diagnosis and follow-up of VUR and to propose a work up protocol.

METHODS: We describe the imaging techniques: VCUG, uttrasound, intravenous urography, bladder-ultrasound, DMSA, MRI, and their role in the evaluation and follow-up of VUR. We performed a bibliographic review about the topic and present the experience of our working group on VUR.

RESULTS: The bibliographic review shows a clear evolution of the concepts of VUR and also the management algorithms. The
Ignacio Alonso Usabiaga Servicio de Radiología Pediátrica Hospital Materno-Infantil Avda. Arroyo de los Angeles s/n 29009 Malaga. (España).

ialonsousa@gmail.com 
concepts of congenital renal lesion without urinary tract infection (UTI) or acquired lesion after UTI are clearly differentiated in the most recent reviews. Reflux is passing from being the center of the problem to a secondary phenomenon in relation to UTI, and this is leading to a change of diagnostic strategy, less and less invasive.

CONCLUSIONS: VCUG has been to date the first and indisputable technique for the management of VUR, mainly in the diagnostic phase, but technological advances in the area of ultrasound (ultrasound contrasts, harmonic image, etc.) have converted ultrasound in the first imaging technique for the management of VUR in pediatric age. On the other hand, work-up algorithms have changed due to the great impact prenatal diagnosis is having in the management of urinary tract anomalies.

Keywords: Urinary tract infection. Prenatal diagnosis Fetal renal dilation. VCUG. Bladder-ultrasound. Renal ultrasound. Vesicoureteral reflux.

\section{INTRODUCCIÓN}

El manejo de los niños con RVU sigue siendo controvertido y la gran cantidad de trabajos publicados en las dos últimas décadas nos muestran los cambios de actitud que se han ido produciendo no solo en el tratamiento o en los aspectos diagnósticos sino en el verdadero fondo de la cuestión: la importancia que tiene el RVU en la lesión renal permanente $y$, como consecuencia, en la evolución de la función renal (1-3). Los avances en el diagnóstico prenatal están cambiando las indicaciones de las técnicas de imagen ya que actualmente la detección prenatal de una anomalía en la vía urinaria está siendo la primera causa de investigación postnatal de la presencia de RVU junto a la indicación clásica de infección urinaria en el lactante.

Por otro lado los avances tecnológicos, con gran desarrollo de las técnicas de ultrasonidos que permiten una inocua y excelente visualización del riñón y de toda la vía urinaria del niño con nuevas aportaciones mediante la utilización de contrastes ecográficos (Cistosonografía), ya han desbancado definitivamente en algunos centros al CUMS que había sido hasta ahora el "patrón oro" en el diagnóstico y seguimiento del RVU.

La visión anatómica más exacta -y tradicionalmente preferida por los urólogos- siempre la ha proporcionado la U.I.V., pero la necesidad de utilizar radiaciones ionizantes junto al desarrollo de sondas ecográficas de alta frecuencia y la aplicación de la RM -muy útil sobre todo cuando la vía urinaria está dilatada - ha hecho pasar a un segundo plano aquella técnica en la edad pediátrica.

Otro de los debates permanentes en el RVU es la periodicidad en el empleo de las técnicas de imagen. En los últimos años hay una tendencia a espaciar los controles de imagen, sobre todo los agresivos, y dar una clara prioridad a los controles clínicos y analíticos ya que la fun- ción renal y la ausencia de infección en la orina son los parámetros mas importantes a valorar en el curso de esta patología.

\section{Descripción de las técnicas}

\section{ECOGRAFÍA RENAL}

Es la técnica más utilizada en la evaluación del aparato urinario porque nos permite valorar el tamaño renal - imprescindible en la época de crecimiento para evaluar posibles estancamientos en el mismo- , la dilatación del sistema pielocalicial y de los uréteres así como ver la pared y la luz vesical. En los últimos años hemos asistido a una verdadera revolución de la ecografía con el desarrollo de una "nueva" tecnología:

- Transductores de alta frecuencia

- Doppler color

- Imagen armónica

- Contrastes ecográficos

- 3D y $4 D$

El desarrollo del Doppler color nos permite ver la vascularización renal y podemos valorar la perfusión renal

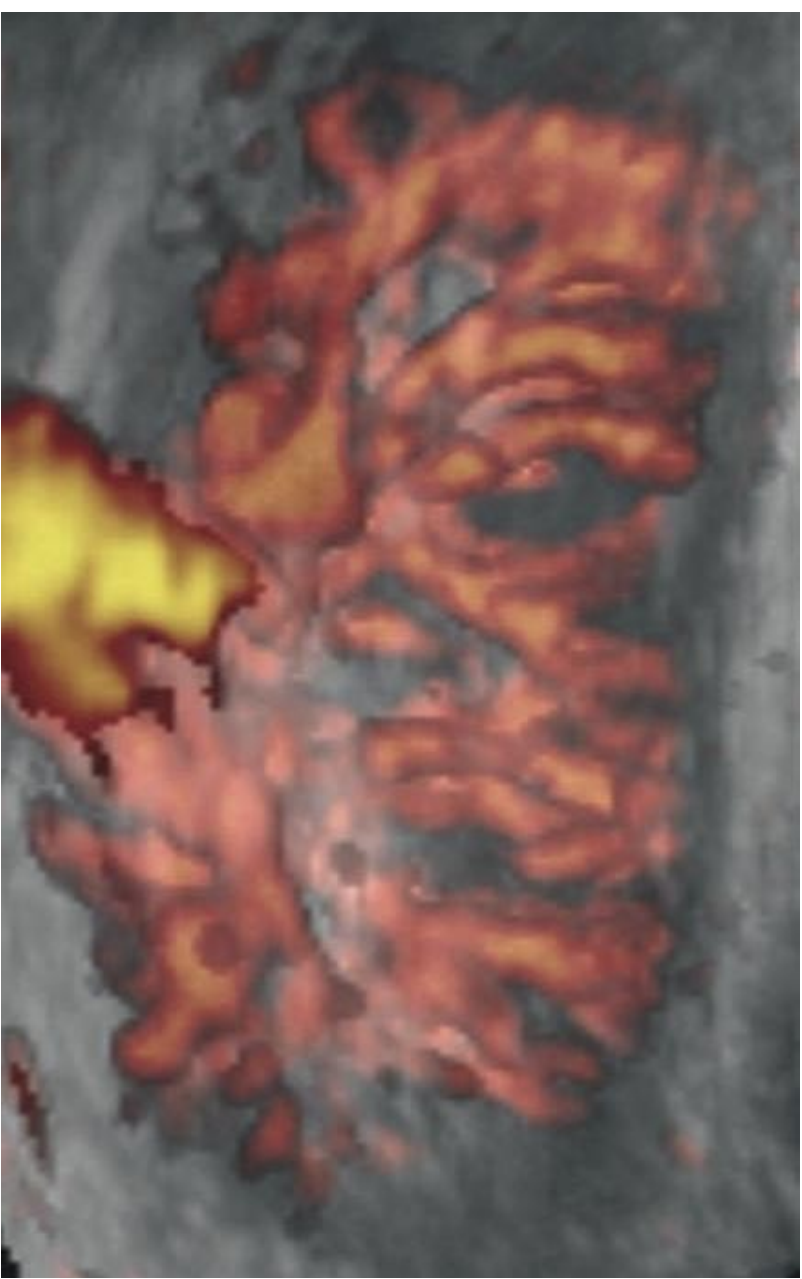

FIGURA 1. Doppler color: vascularización renal. 


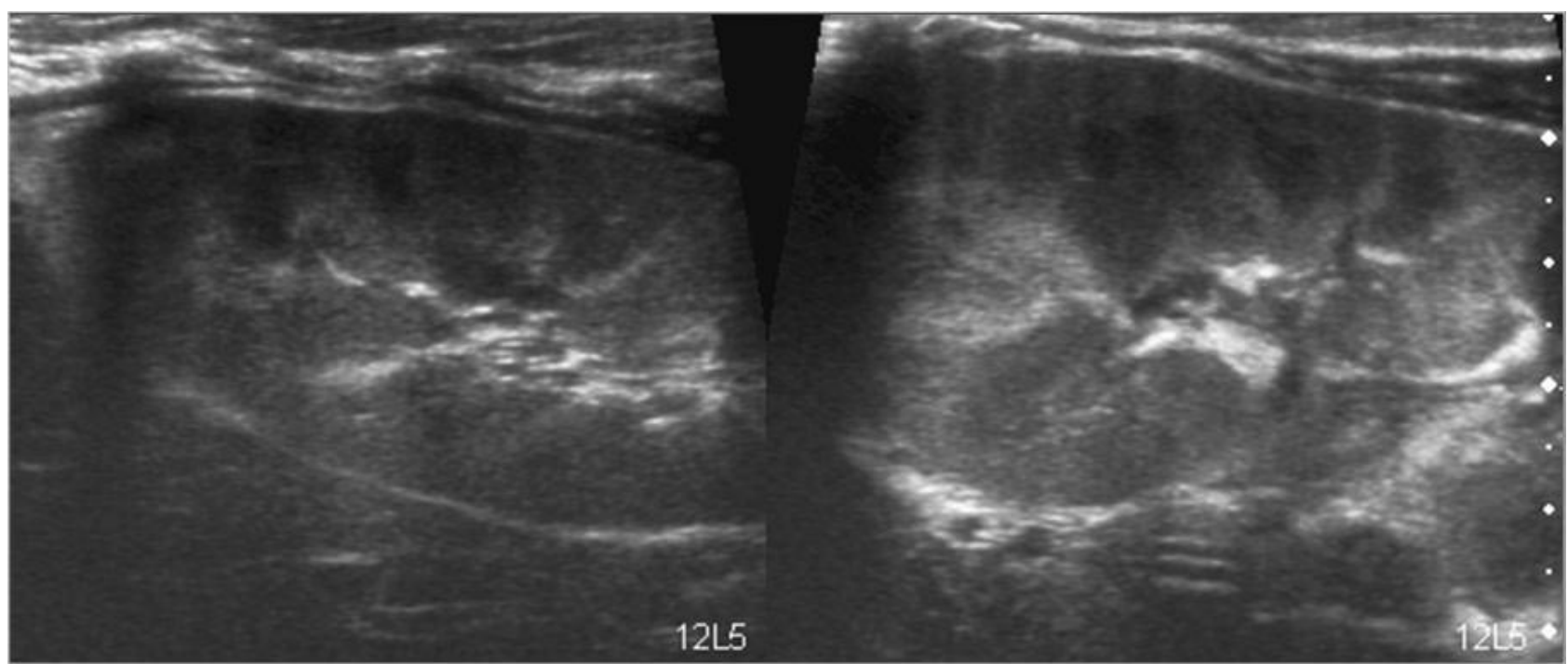

FIGURA 2. Pielonefritis aguda:a la izquierda, riñón normal. A la derecha, aumento del volumen del polo superior con cambios en la ecogenicidad del parénquima.

(Figura 1), detectando posibles áreas de hipoperfusión en los casos de pielonefritis aguda. La sensibilidad es menor que la del DMSA pero la aplicación de los contrastes ecográficos de $2^{a}$ generación junto a la técnica de "imagen armónica" puede sustituir progresivamente a la medicina nuclear en la fase aguda de la infección de orina (Figuras 2-4).

La utilización de transductores de alta frecuencia, imprescindibles en pediatría, permite una mejor visión anatómica del riñón y ayuda a valorar adecuadamente la diferenciación cortico-medular y posibles cicatrices en la corteza renal aunque la sensibilidad en la identificación de zonas cicatriciales sigue siendo mas baja que la del DMSA.

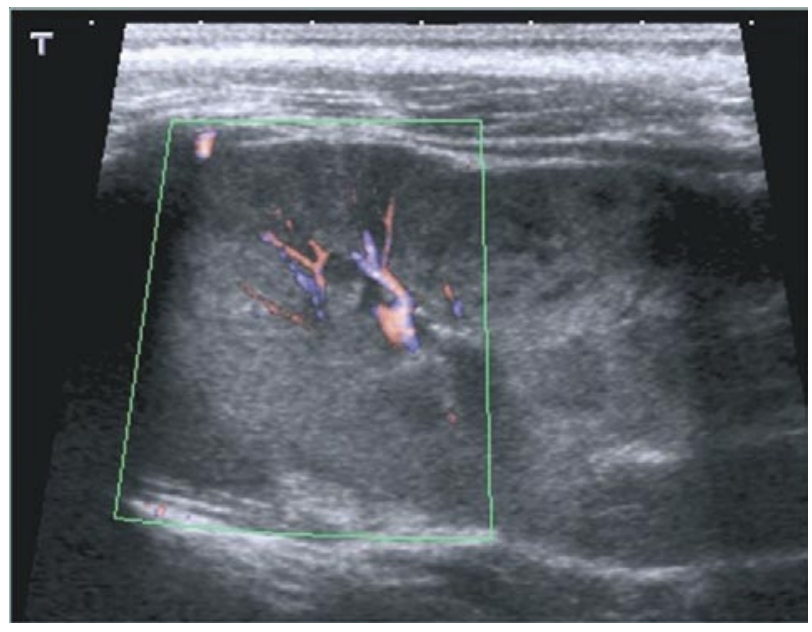

FIGURA 3. PNA: Doppler color. Hipoperfusión en polo superior.
La ecografía 3D y $4 \mathrm{D}$, que en otros campos está teniendo unas aplicaciones reales, puede tener algún papel en el futuro aunque todavía hay pocos trabajos con resultados relevantes. La mayor exactitud en el cálculo de los volúmenes o la posibilidad de realizar una cistoscopia virtual, están siendo algunas de las primeras aplicaciones en fase de investigación $(4,5)$ (Figuras 5,6).

\section{UROGRAFÍA INTRAVENOSA (UIV)}

Es la técnica de imagen mas empleada durante muchos años en la valoración de la vía excretora pero está cayendo en desuso por el auge de otras técnicas menos agresivas (que no necesitan radiación ni contraste iodado). Es la técnica que mejor ha definido la vía urinaria, pero el

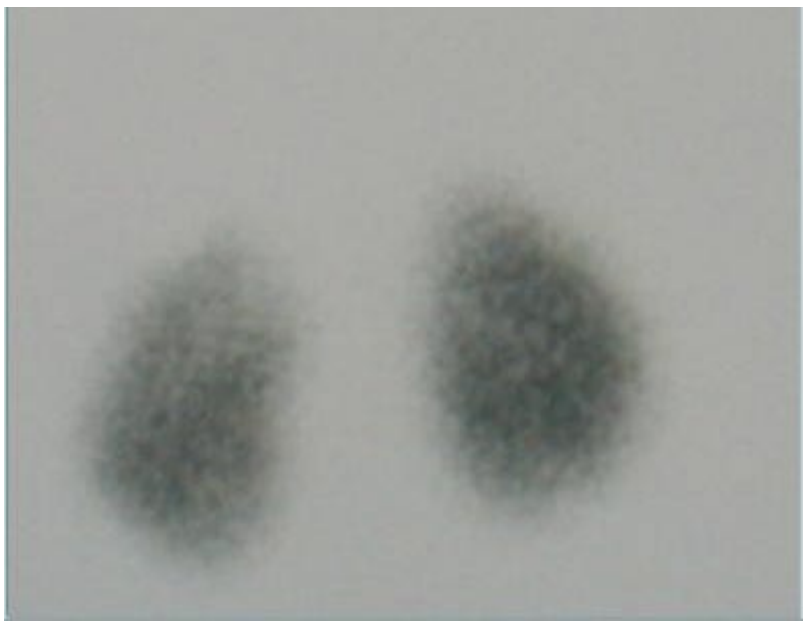

FIGURA 4. PNA: DMSA. Hipocapación en polo superior renal. 
desarrollo de los Ultrasonidos (US), la Tomografía Computarizada (CT) y la Resonancia Magnética (RM) ha hecho que la visión más anatómica también sea alcanzada por dichas técnicas. Aunque en los adultos su empleo sigue siendo generalizado, en la edad pediátrica debe quedar reservada a casos muy puntuales como por ej: dobles sistemas difíciles de definir, casos dudosos de estenosis pieloureteral (si no contamos con otras técnicas). En caso de realización de la UIV se deben restringir las radiografías al mínimo y en muchas ocasiones hacemos " placa única" a los 10-15 minutos (Figura 7).

\section{Ventajas:}

- Mejor visión anatómica de la vía urinaria.

\section{Inconvenientes:}

- Necesidad de radiación.

- Posibilidad de reacción al contraste i.v.

- Poca utilidad en las primeras semanas de vida.

\section{CUMS (Cistouretrografía miccional seriada)}

Sigue siendo la técnica más utilizada en el diagnóstico inicial del RVU aunque ya no lo es en el seguimiento del mismo debido sobre todo a la alta dosis de radiación necesaria para su realización. La clasificación internacional de los grados de reflujo (6) se ha basado en esta técnica (Figura 8). Se debe realizar siempre que se sospeche un RVU secundario, aunque hay autores que incluso en estos casos defienden la realización de una Cistosonografía (CS) como técnica inicial $(7,8)$. La CUMS valora con mas exactitud el cuello vesical y la uretra posterior por lo que nos permite el diagnóstico de la patología uretral (Figura 9) y también ayuda a valorar las disfunciones vesicales al plasmarse en la fase miccional la imagen de un cuello vesical anormal con hipertonía del esfínter interno en las micciones aberrantes de los reflujos, sobre todo de alto grado, por la contracción insistente del detrusor. Es también la técnica que mejor detecta la hipertonía del esfinter externo tan frecuente sobre todo en las niñas con micción patológica (Figura 10) y que está relacionada con ITU de repetición (9).

Se debe realizar en condiciones de asepsia con limpieza de genitales previa a la cateterización de la uretra.

No se debe inflar un balón intravesical para evitar excesiva presión sobre el trígono durante la prueba.

Se debe utilizar la fluoroscopia el tiempo imprescindible y de forma intermitente aunque esto disminuya la tasa de deteccción de los RVU de bajo grado que muchas veces aparecen de forma esporádica y son de escaso significado.

\section{Ventajas:}

- La mejor visión anatómica del tracto de salida vesical y de la uretra.

\section{Inconvenientes:}

- Alta dosis de radiación.

- Menor sensibilidad para detectar los reflujos grado I.

\section{CISTOSONOGRAFÍA}

Es una modalidad de cistografía que utiliza un ecógrafo para la visualización de la vía urinaria. Se reali$z a$, igual que en la CUMS, un sondaje vesical a través del cual se instila un contraste que es un potenciador de la señal ecográfica (ecopotenciador) que produce una imagen de alta ecogenicidad en la luz de la vía urinaria (vejiga, uréter, pelvis, cálices y uretra) (Figuras 11 y 12). El agente de contraste es galactosa en forma de micropartículas estabilizadas con ácido palmítico (Levovist, Levograf) diluido y agitado en suero fisiológico a dosis de 0,5-1 ml/ kg de peso. La introducción del contraste debe ser muy lenta para evitar el "efecto sombra" y mantener una buena trasmisión acústica.

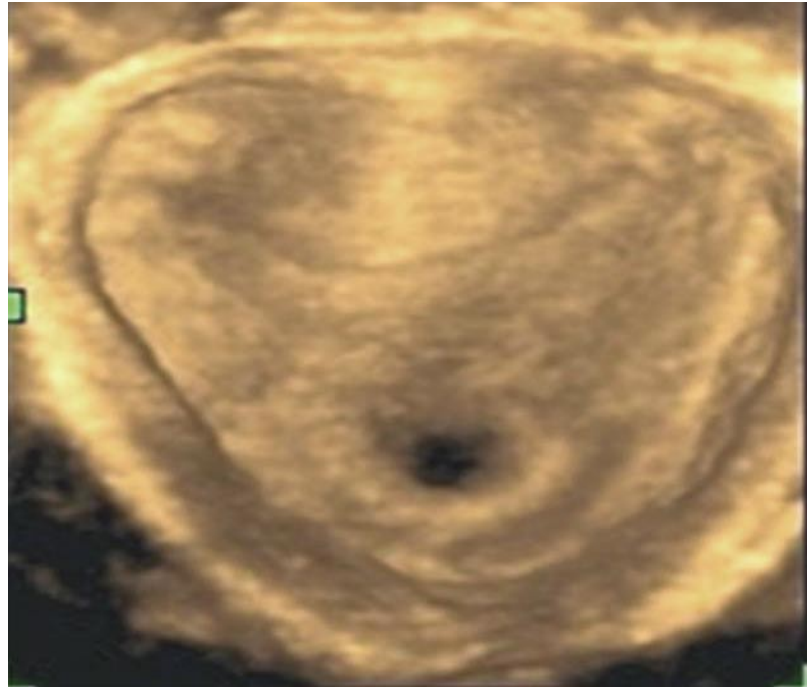

FIGURA 5. 3 D. Cistoscopia virtual. Visión del trígono. *

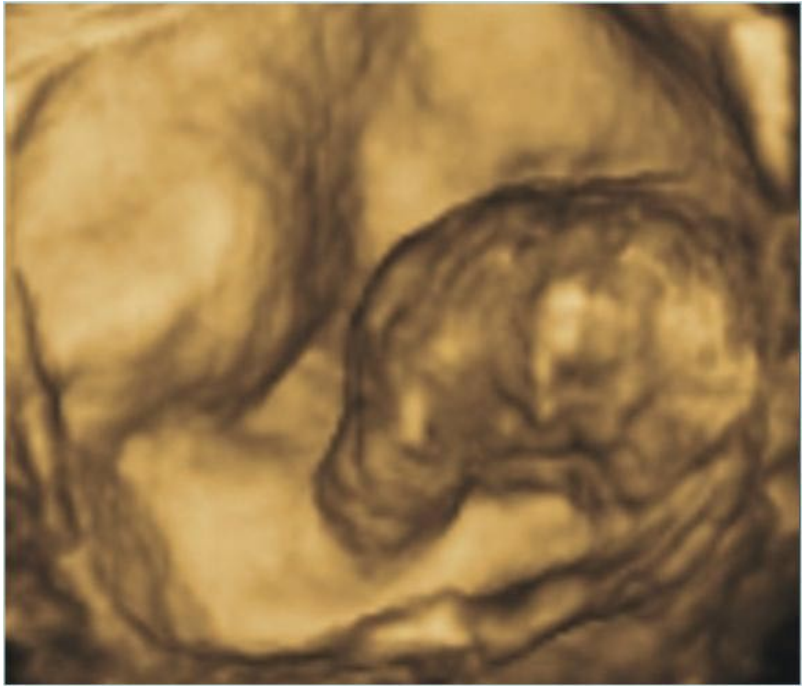

FIGURA 6. 3D. Ureterocele ectópico. *

*Imágenes cedidas por la Unidad de Ecografía del Centro Gutenberg (Málaga). 
Hay nuevos contrastes ecográficos, como el Sonovue (microburbujas de hexafluoruro de azufre), que aún no está homologado para su utilización en niños.

El empleo de equipos de ultrasonidos con programas específicos, que combinan la utilización de armónicos (10) y ondas con bajo índice mecánico, mejoran la visión del contraste a una menor concentración del mismo (menor coste) y mayor tiempo de estabilidad de las burbujas lo que aumenta la sensibilidad en la detección del RVU. Un pequeño truco para aumentar el tiempo de activación de las burbujas es aspirar con la misma jeringa que hemos hecho la introducción del contraste y volverlo a introducir rápidamente consiguiendo de nuevo que la vejiga "se ilumine".

\section{Ventajas:}

- No utilización de radiación ionizante.

- Valoración completa del aparato urinario a la vez que la identificación del RVU .

\section{Inconvenientes:}

- Menor sensibilidad en la detección del reflujo grado I.

- Dificultad para emplear la misma clasificación del RVU que en la CUMS.

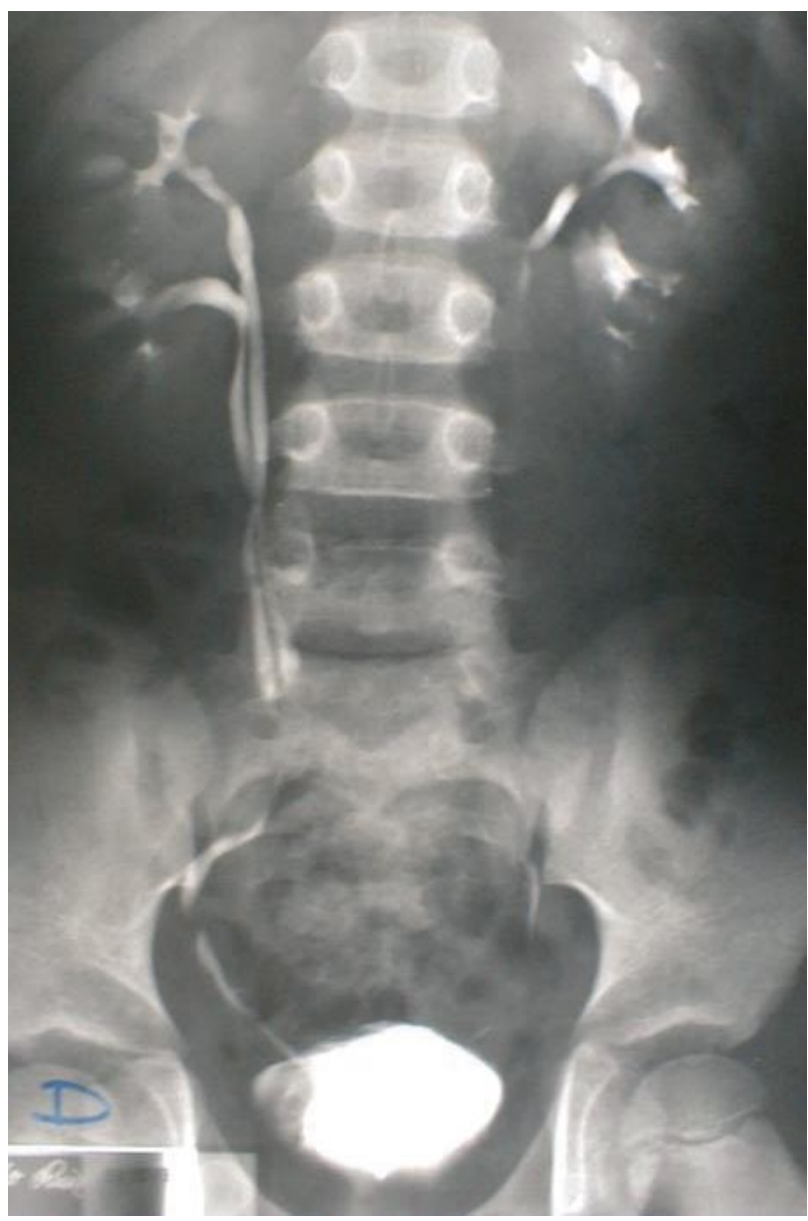

FIGURA 7. Urografía i.v. Doble sistema. Pielonefritis crónica en riñón izquierdo.
- Mayor coste económico de los contrastes ecográficos.

- Necesidad de mayor número de equipos de ultrasonidos.

\section{CISTOGRAFÍA ISOTÓPICA}

Existen dos formas de cistografía isotópica (Cl): la directa, en la que se rellena la vejiga con un radiotrazador (99mTc-azufre coloidal o $99 \mathrm{mTc}$-DTPA) y la cistografía isotópica indirecta, que se realiza al final de un renograma, cuando la vejiga está repleta. Este último método requiere la colaboración del paciente que debe ser capaz de retener la orina y vaciar la vejiga cuando se le indique, por lo que es difícil realizarla en niños.

En la cistografía isotópica directa, se introduce una sonda en la vejiga y se infunde lentamente una solución salina estéril con el radioisótopo. La adquisición se realiza de forma continua desde el comienzo hasta la fase de máxima presión vesical con el paciente en decúbito supino y la gammacámara sobre el abdomen $(11,12)$. Se puede utilizar en la fase diagnóstica del RVU cuando las consideraciones anatómicas no son el objetivo, ya que no tiene una buena visión anatómica, aunque su indicación más extendida es el seguimiento de niños con RVU diagnosticado y que siguen un tratamiento conservador. También está indicada para el despistaje en hermanos de niños con RVU.

\section{Ventajas:}

- Menor exposición a radiación ionizante.

- Mayor sensibilidad para detectar RVU de bajo grado.

- No requiere sedación.

\section{Desventajas:}

- Poca resolución espacial y mala visión anatómica.

- No se puede utilizar la misma clasificación que para la CUMS.

- No sirve para valorar el tracto de salida vesical ni la uretra.

- No visualiza el reflujo pielosinusal.

\section{ESCINTIGRAFÍA CON DMSA}

Consiste en el estudio de la corteza renal, tras la administración intravenosa de un radiotrazador, el $99 \mathrm{mTc}$ DMSA (ácido dimercapto-succínico), que se acumula en los túbulos proximales.

Permite un estudio morfológico y funcional de la corteza renal. La acumulación máxima en la corteza renal ocurre entre las 2-6 horas de su inyección.

Su asociación con SPECT mejora la resolución espacial y es posible que aumente su sensibilidad. Es la técnica de elección para la valoración de cicatrices renales. En la fase aguda de una pielonefritis detecta las zonas de hipoperfusión por edema intersticial pero un DMSA patológico no es indicativo de la presencia de un $\operatorname{RVU}(13,14)$. Sin embargo es la técnica que identifica mas precozmente las cicatrices renales permanentes $(6$ meses después del episodio agudo de pielonefritis) (Figura 13).

\section{Ventajas:}

- Muy sensible para la detección de cicatrices corticales.

- No precisa sedación (basta con la inmovilización). 


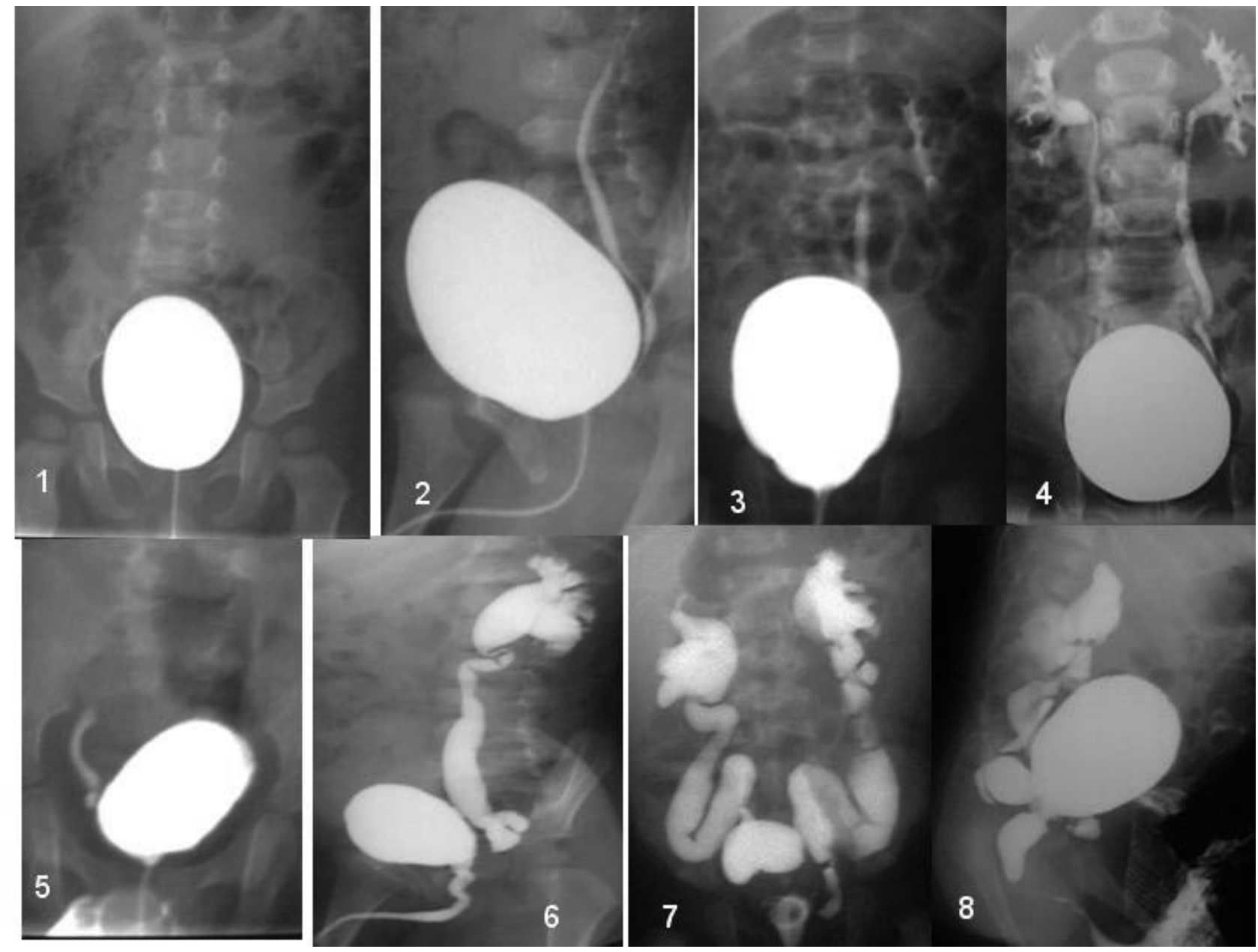

FIGURA 8. CUMS. 1: normal.

2,3,4: RVU primario, diferentes grados.

5,6: RVU grado HV con divertículo de Hutch

7,8: RVU secundario grado IV-V: Válvulas de uretra posterior.

\section{Inconvenientes:}

- No sirve para el diagnóstico del reflujo sino de sus secuelas-complicaciones.

\section{RESONANCIA MAGNÉTICA}

Es una técnica imagen que está demostrando cada vez más su utilidad en la valoración urológica en la infancia sobre todo en las malformaciones complejas y en las situaciones en las que la dilatación de la vía urinaria es el principal hallazgo.

Proporciona información anatómica y funcional del sistema excretor (15-17) y en el futuro está llamada a ser una técnica de primera línea en la valoración urológica porque va a fusionar una información anatómica precisa con una valoración de la función renal mas exacta que el resto de las técnicas incluida la medicina nuclear.

Existen distintos tipos de estudios de RM que pueden utilizarse para la evaluación del aparato urinario:
- RM renal convencional: permite la valoración de cicatrices renales o bien en el contexto de una infección aguda del tracto urinario superior pone de manifiesto áreas de pielonefritis o complicaciones infecciosas (abscesos).

- URO-RM: aporta información del sistema excretor desde los cálices hasta la vejiga.

Existen dos formas:

1- La RM-urografía estática, que utiliza secuencias de pulsos muy potenciadas en T2, y va a poner de manifiesto los líquidos estáticos. Precisa que la vía excretora esté dilatada. Es muy útil en las malformaciones complejas del aparato urinario (Figura 14) y en situación de insuficiencia renal (porque no es necesaria la administración de contraste) pero no aporta información sobre la función renal.

2- La RM-urografía excretora o funcional, es similar a una urografía intravenosa convencional. Precisa la administración de gadolinio intravenoso (Gd-DTPA), que se elimina 


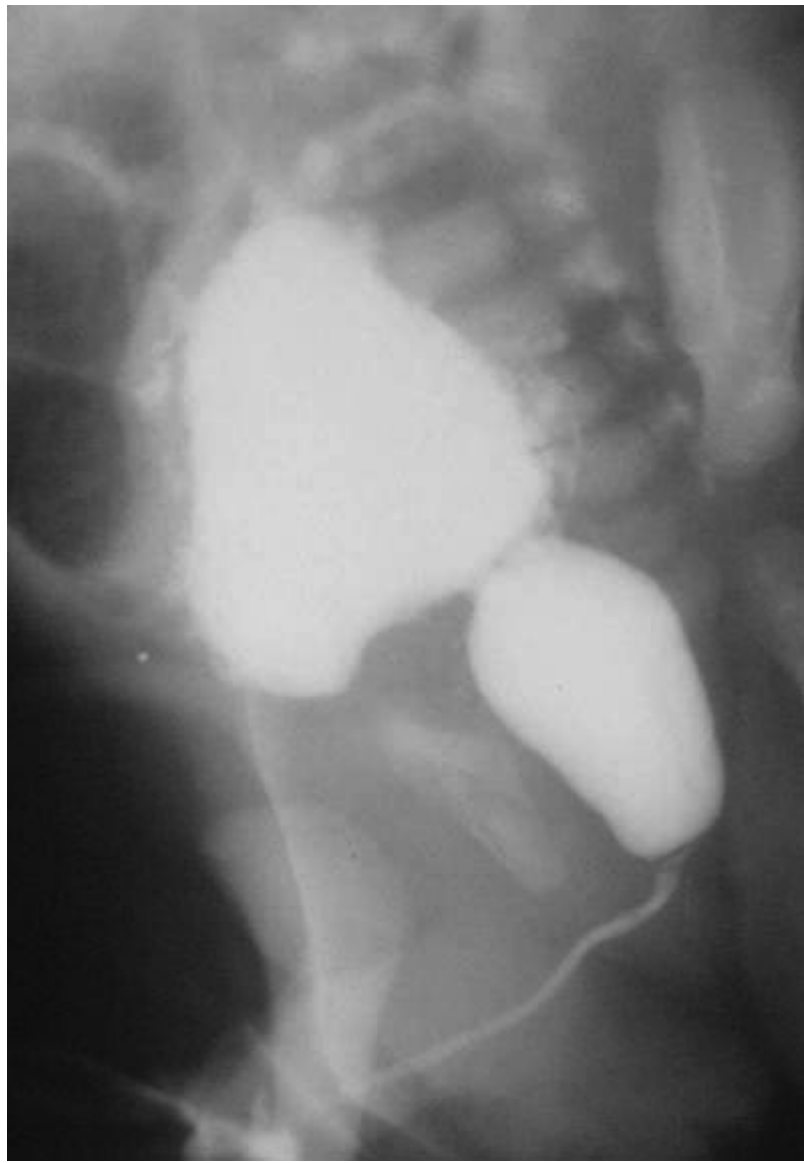

FIGURA 9. CUMS. Fase miccional. Válvulas de uretra posterior.

por filtración glomerular, y furosemida como diurético. Utiliza secuencias T1 EG 3D. Proporciona imágenes de alta calidad del tracto urinario dilatado y no dilatado e informa sobre la función renal por separado de los dos riñones e incluso de áreas concretas dentro de un riñón (Figura 15). Sin embargo el uso del Gadolinio debe ser utilizado con precaución en los casos de insuficiencia renal ya que se han descrito casos de Fibrosis Sistémica Nefrogénica y se considera un factor de riesgo la inmadurez funcional renal de los niños menores de 1 año.

\section{Ventajas:}

- No utiliza radiación ionizante.

- No utiliza contraste yodado.

- Capacidad multiplanar con alta resolución espacial y de contraste de tejidos.

- Proporciona información morfológica y funcional.

\section{Inconvenientes:}

- Largo tiempo de exploración y necesidad de sedación en el niño pequeño.

- Poca disponibilidad y alto coste.

- Complejidad técnica.

- No se debe utilizar en niños menores de 1 año con mala función renal.

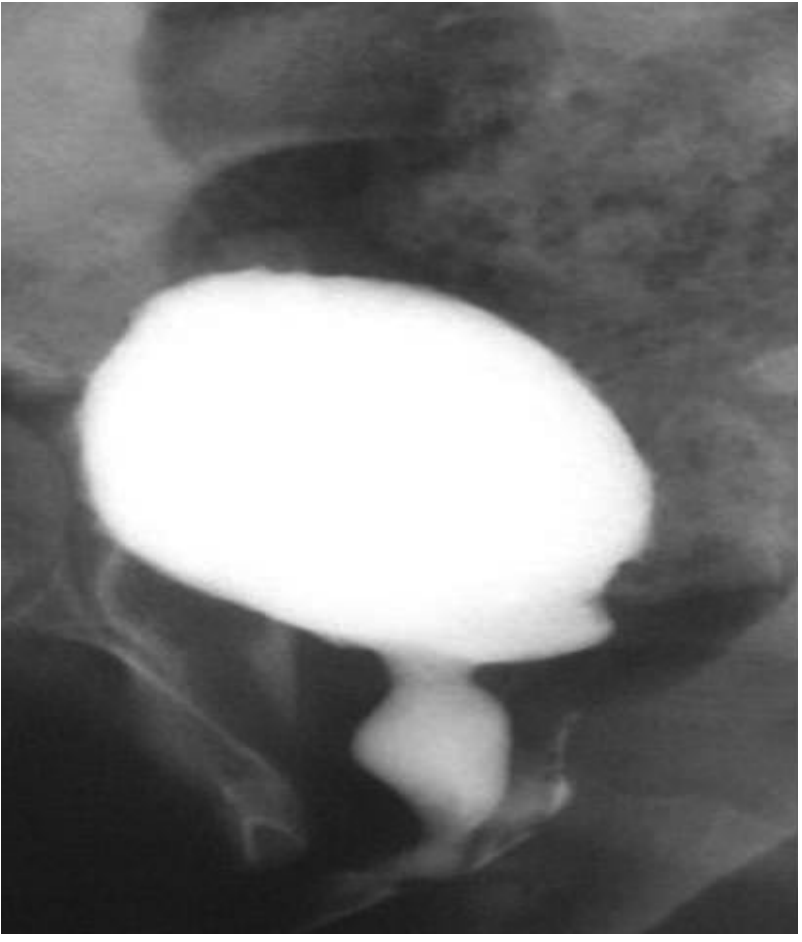

FIGURA 10. CUMS. Fase miccional en niña. Hipertonía del esfinter externo: "uretra en trompo".

\section{DISCUSIÓN}

Una parte muy significativa de la actividad de los servicios de radiología pediátrica giran en torno a recién nacidos con diagnóstico prenatal de alguna anomalía o a lactantes con procesos infecciosos. De ellos, una buena parte tienen su origen en la vía urinaria con una gran prevalencia del RVU. El tratamiento de estos lactantes ha cambiado en los últimos años y ha pasado a ser más conservador y muchas veces puramente profiláctico porque el diagnóstico de RVU se hace sin que haya habido sintomatología clínica, como es en casi todos los casos de diagnóstico prenatal. Por otro lado, la historia natural de la mayoría de los RVU de bajo y medio grado (I-IIIII) diagnosticados en los primeros meses de la vida es hacia su desaparición con tratamiento conservador (18-20).

En los últimos años se ha desechado el concepto de "nefropatía de reflujo" y se ha vuelto a la nomenclatura de pielonefritis crónica. La ITU es la principal causa de lesiones permanentes renales en la vida postnatal, pero la descripción de lesiones renales en la vida prenatal y en recién nacidos asintomáticos sin ITU ha hecho emerger el concepto de lesiones que podemos denominar congénitas o, lo que sería casi lo mismo, displásicas, sin que haya un agente infeccioso implicado y que probablemente tienen su origen en el inicio "erróneo" de la yema ureteral con un RVU intrauterino muy precoz asociado a una mala diferenciación del metanefros en tejido renal maduro. Todos estos cambios están cuestionando los protocolos de estudio en los lactantes con ITU o con alguna anomalía en la vía urinaria detectada en su vida fetal $(18,20,21,23-25)$. 


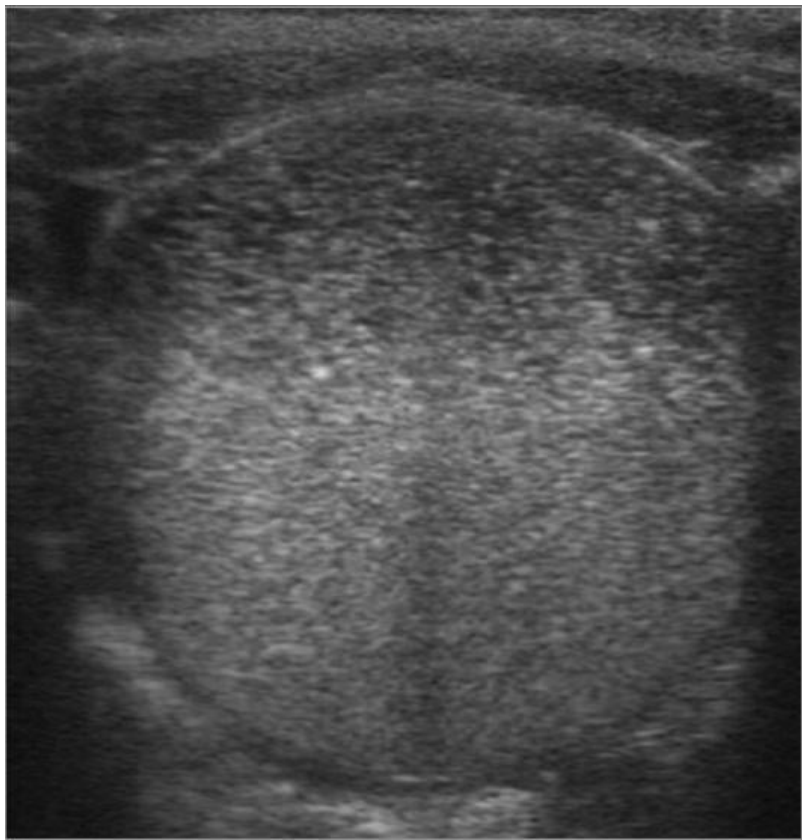

FIGURA 1 1. Cistosonografía. Vejiga rellena de burbujas de contraste ecográfico.

El pronóstico de estos niños está condicionado por la severidad del RVU, por la presencia de anomalías asociadas (RVU secundario), pero sobre todo por la presencia de lesión renal en el momento del diagnóstico. El éxito en el tratamiento también está en relación con varios factores bien establecidos:

- Grado de reflujo

- Bilateralidad

- Grado de dilatación ureteral

- Presencia de disfunción vesical

- Anomalías asociadas.

Por lo tanto el objetivo de las técnicas de imagen en la investigación del RVU debe ser la obtención de respuestas a las siguientes preguntas:

- ¿ Cómo están los riñones?

- ¿ Hay reflujo?

- ¿ Es un reflujo primario o secundario?

- ¿ Qué grado de reflujo?

- ¿ Cómo están los uréteres?

- ¿ Hay disfunción vesical?

Las diferentes técnicas de imagen empleadas deben responder a estas preguntas porque su respuesta va a determinar no solo el pronóstico sino el manejo y tipo de tratamiento al que van a ser sometidos estos niños.

\section{$¿$ Cuando realizar pruebas de imagen?}

1- Diagnóstico prenatal de anomalía en la vía urinaria.

La dilatación de la pelvis renal es el hallazgo más frecuente descrito en los estudios fetales. En el $2^{\circ}$ trimestre de la gestación se considera normal una pelvis medida en su diámetro AP (plano axial) menor a $5 \mathrm{mms}$. Después de la semana 30 se considera normal un diámetro menor a $7 \mathrm{mms}$. La clasificación de la dilatación renal establecida por la Sociedad de Urología fetal y que es utilizada en la valoración postnatal es:

Leve: $7-10 \mathrm{mms}$.

Moderada: $10-20 \mathrm{mms}$.

Severa: > 20 mms.

La dilatación puede ser exclusivamente de la pelvis o afectar a los cálices y uréteres. Se acepta que siempre que se haya detectado dilatación en cualquier grado se debe realizar una ecografía en el primer mes de vida (21). Se recomienda realizar el estudio entre la $2^{\underline{a}}$ y $4^{\underline{a}}$ semanas, ya que en los primeros días de vida hay una relativa oliguria que puede infravalorar el grado de dilatación postnatal. La excepción son las dilataciones severas o la sospecha de obstrucción uretral o vejiga neurógena que precisan estudio inmediato $y$, en caso de confirmación, un tratamiento precoz.

Si la dilatación es leve y la ecografía no muestra dilatación de cálices o uréteres no hacemos pruebas adicionales ya que, aunque la incidencia de RVU en estos niños es más alta que en los que no se ha detectado dilatación, la mayoría de los reflujos son de bajo grado y suelen desaparecer espontáneamente durante los dos primeros años de vida (22-25).

Es recomendable que a estos lactantes con dilataciones leves ( $<10 \mathrm{mms}$.) se les realice otra ecografía a los 3-6 meses de vida para comprobar la evolución de la dilatación ya que se han descrito casos de progresión hacia la Estenosis Pieloureteral.
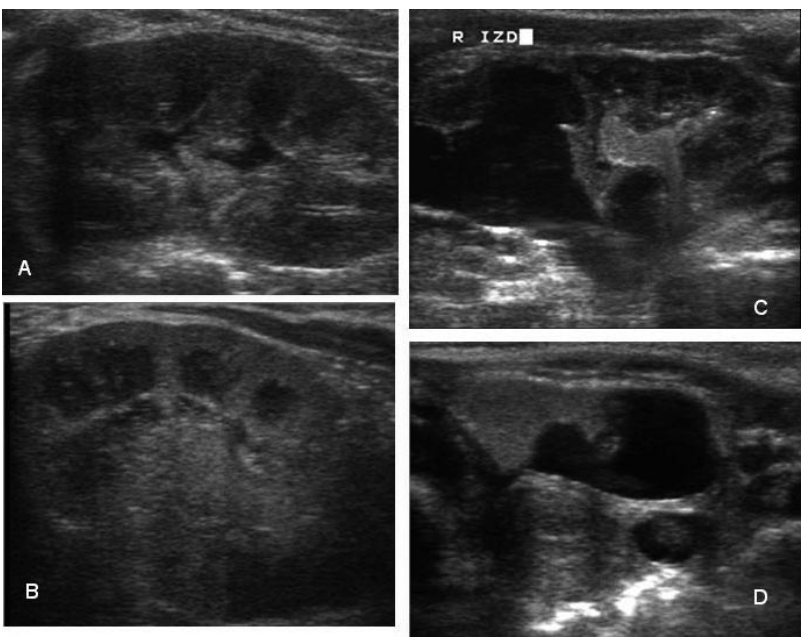

FIGURA 12. Cistosonografía. A: RVU con contraste en la pelvis renal (grado II). B: RVU grado III.

C: Doble sistema. RVU al inferior e hidronefrosis del superior.

D: Doble sistema. Defecto de replección vesical por ureterocele ectópico y contraste en el uréter del sistema superior. 


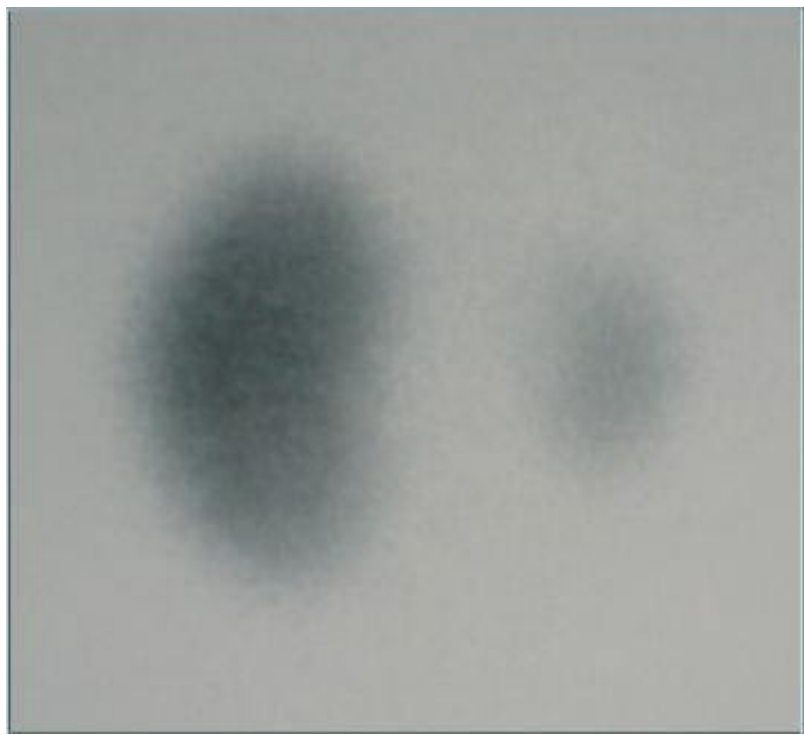

FIGURA 13. DMSA. Pielonefritis crónica.

En caso de diagnóstico prenatal de anomalías de posición renal o displasia multiquística también está indicado el despistaje de RVU. *Algoritmo de Dilatación Prenatal (Cuadro I).

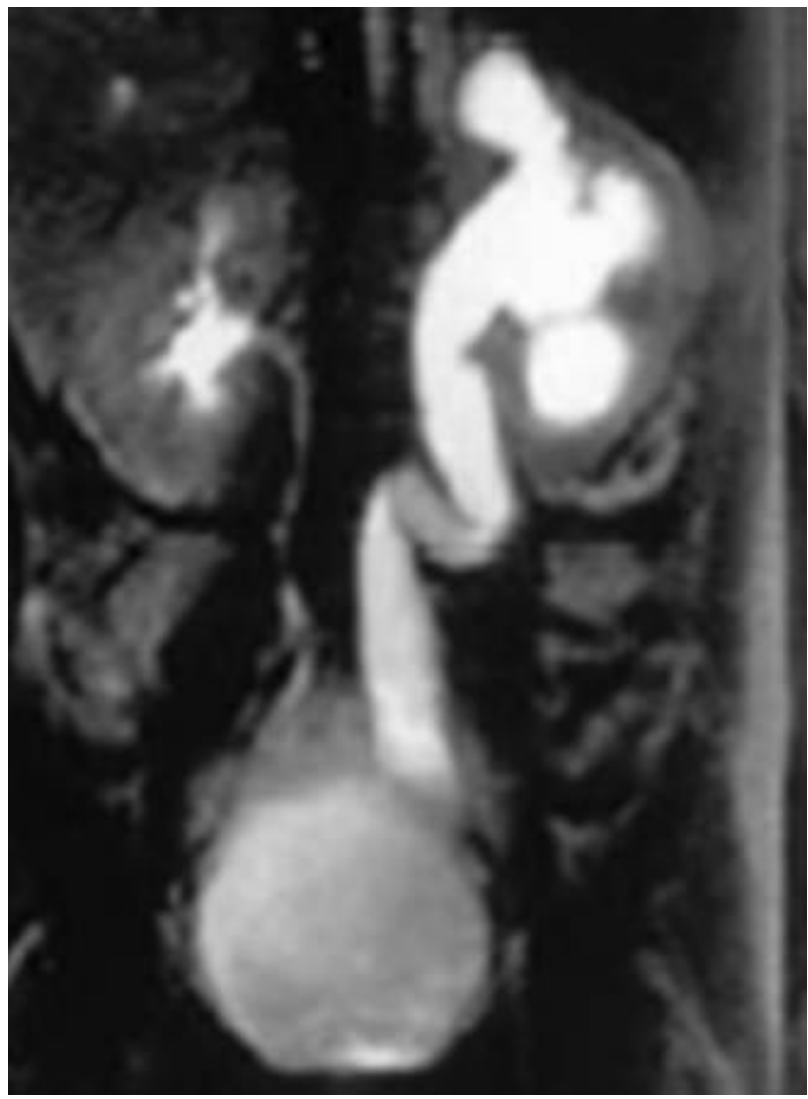

FIGURA 15. RM funcional. Hidronefrosis izquierda.

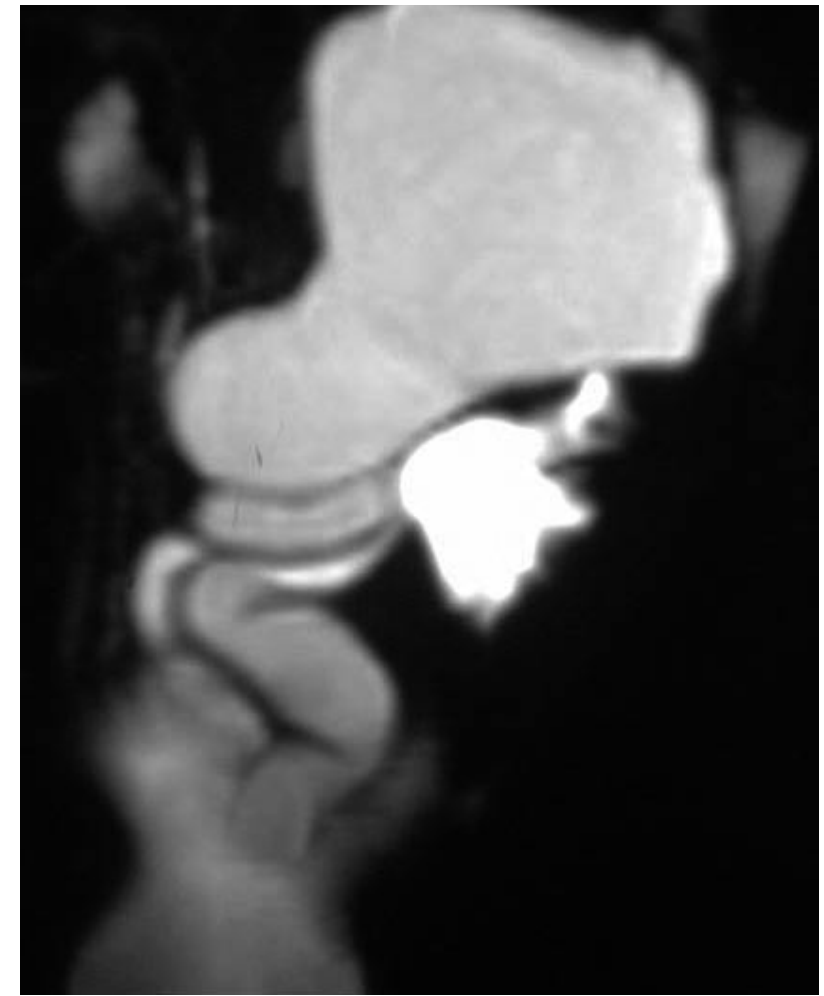

FIGURA 14. RM estática. Doble sistema completo.

\section{2- Infección de orina.}

Es la principal indicación en la investigación del RVU. Aunque parece que el RVU en ausencia de infección puede producir lesión renal, se ha demostrado que la infección de orina con o sin reflujo asociado provoca lesión renal (26). Por lo tanto, la ITU es la principal indicación para la utilización de técnicas de imagen. Hay algunos autores que creen que, en la primera ITU, la demostración del RVU tiene un valor limitado y defienden la realización de una ecografía y un DMSA (27-29). Pero a pesar de algunas excepciones, el verdadero debate o mejor dicho los cambios de actitud en los últimos años van orientados hacia el tipo de técnicas a utilizar (30-32). La mayor exactitud anatómica que permite la CUMS tiene su contrapunto en la gran radiación necesaria para un buen estudio. La mayor sensibilidad de la $\mathrm{Cl}$ y su baja dosis de radiación tiene sus límites en la mala visión anatómica y su dificultad en el estadiaje del RVU. Ha ido ganando terreno la CS por su inocuidad y su aceptable visión anatómica que permite incluso valorar adecuadamente la uretra (33) (Figura 16). En su contra está la menor sensibilidad para la detección de los bajos grados de reflujo pero también, por qué no decirlo, en la necesaria reestructuración de las unidades de ecografía pediátrica ya que es una prueba que requiere personal entrenado y bastante tiempo de exploración en las salas de ultrasonidos, que ya tienen habitualmente un porcentaje alto de ocupación.

Si comparamos las técnicas utilizadas en el diagnóstico del RVU hay varios puntos diferenciales: 
CUMS (Cistouretrografía Miccional Seriada)

- Mejor visión anatómica.

- Mayor exactitud en el estadiaje del RVU.

- Máxima radiación.

$\mathrm{Cl}$ (Cistografía Isotópica)

- Máxima sensibilidad.

- Peor visión anatómica.

- Mínima radiación.

CS (Cistosonografía)

- Ausencia de radiación (cumple criterio ALARA* de protección radiológica de la $\mathrm{CE}$ ).

- Menor sensibilidad.

- Menor visión anatómica.

- Más cara.

*ALARA: as low as reasonably achievable

Los criterios para la utilización de las diferentes técnicas de imagen siempre deben ir encaminados a cumplir criterios de evidencia científica, de eficacia diagnóstica y de influencia en el tratamiento pero también debe valorarse el impacto en términos de invasión, radiación y coste (34).
Por último hay que recordar que el "factor local" juega un papel importante en nuestro medio y los recursos disponibles van a ser responsables de cambios en cualquiera de los algoritmos que establezcamos como punto de partida. *Algoritmo de ITU (Cuadro II).

\section{CONCLUSIÓN}

- El manejo del RVU ha cambiado en todos sus aspectos: diagnóstico, tratamiento y seguimiento por el gran impacto que el diagnóstico prenatal está teniendo en la detección de las anomalías del aparato urinario.

- La ITU es el principal motivo de preocupación en la investigación de la vía urinaria y los esfuerzos diagnósticos deben ir dirigidos a la detección precoz de la lesión renal, que es el factor clave.

- La ecografía se ha convertido en la técnica que más rentabilidad diagnóstica tiene porque los avances tecnológicos en el área de los ultrasonidos permiten valorar el parénquima renal, la vía urinaria y con el uso de "potenciadores de la señal", sustituir progresivamente a la CUMS que hasta ahora ha sido la técnica indiscutible en el diagnóstico del RVU.

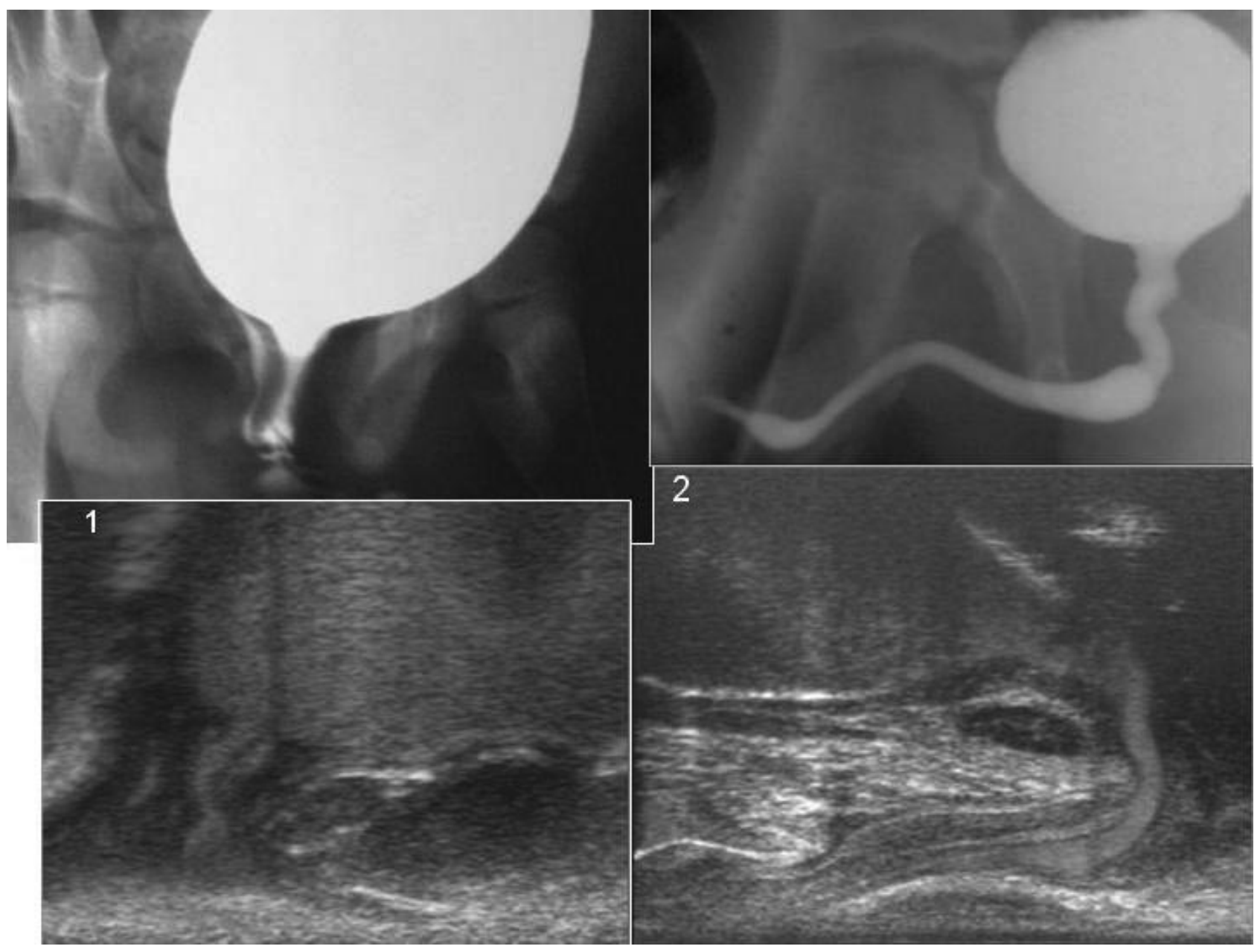

FIGURA 16. CUMS y Cistosonografía. Imagen comparativa de la fase miccional. Uretra masculina y femenina. 
CUADRO I. ALGORITMO DE IMAGEN POSTNATAL DE LA HIDRONEFROSIS FETAL

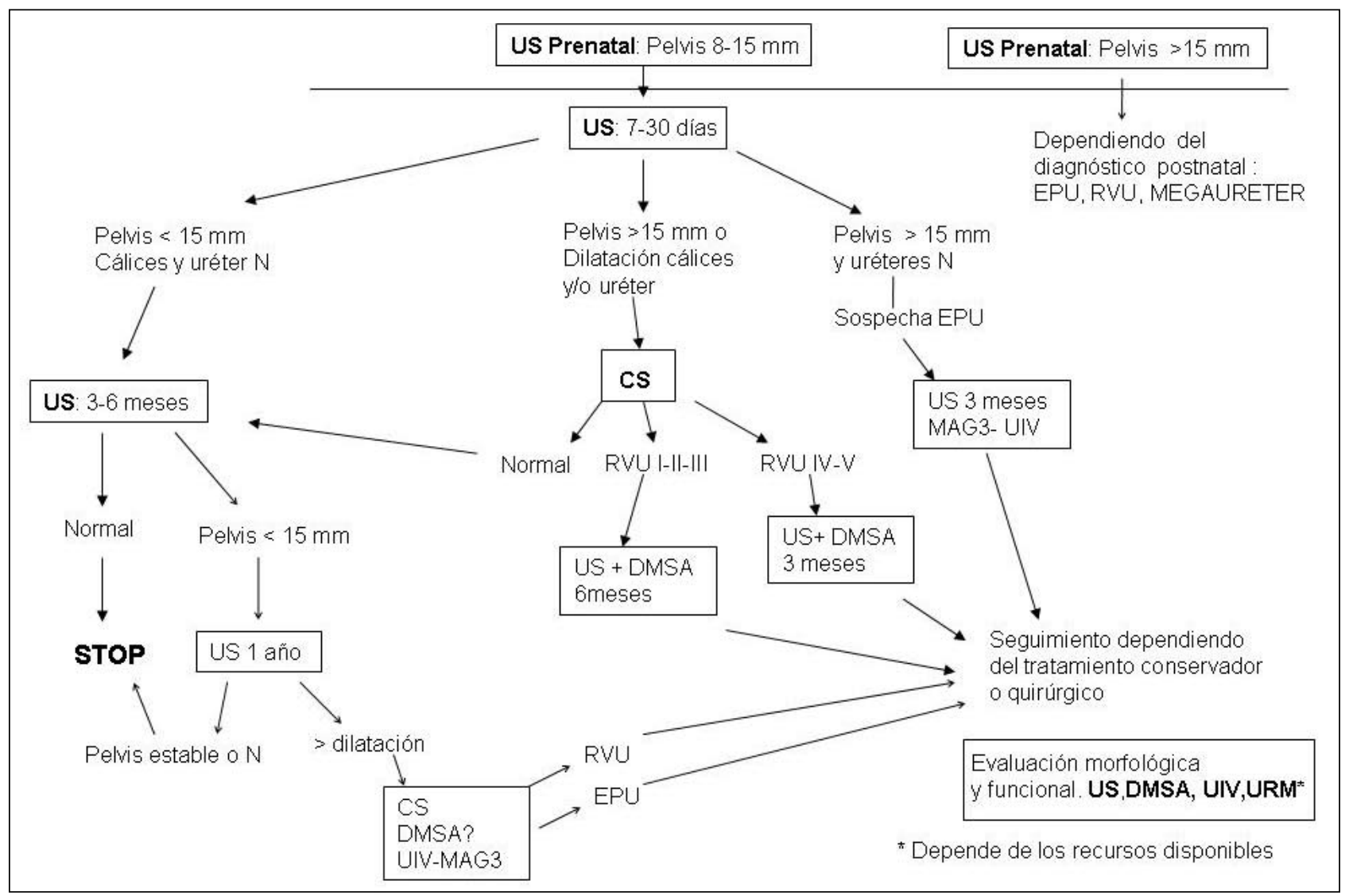

Propuesta de seguimiento en los primeros meses de vida.

CUADRO II. ALGORITMO DE ITU

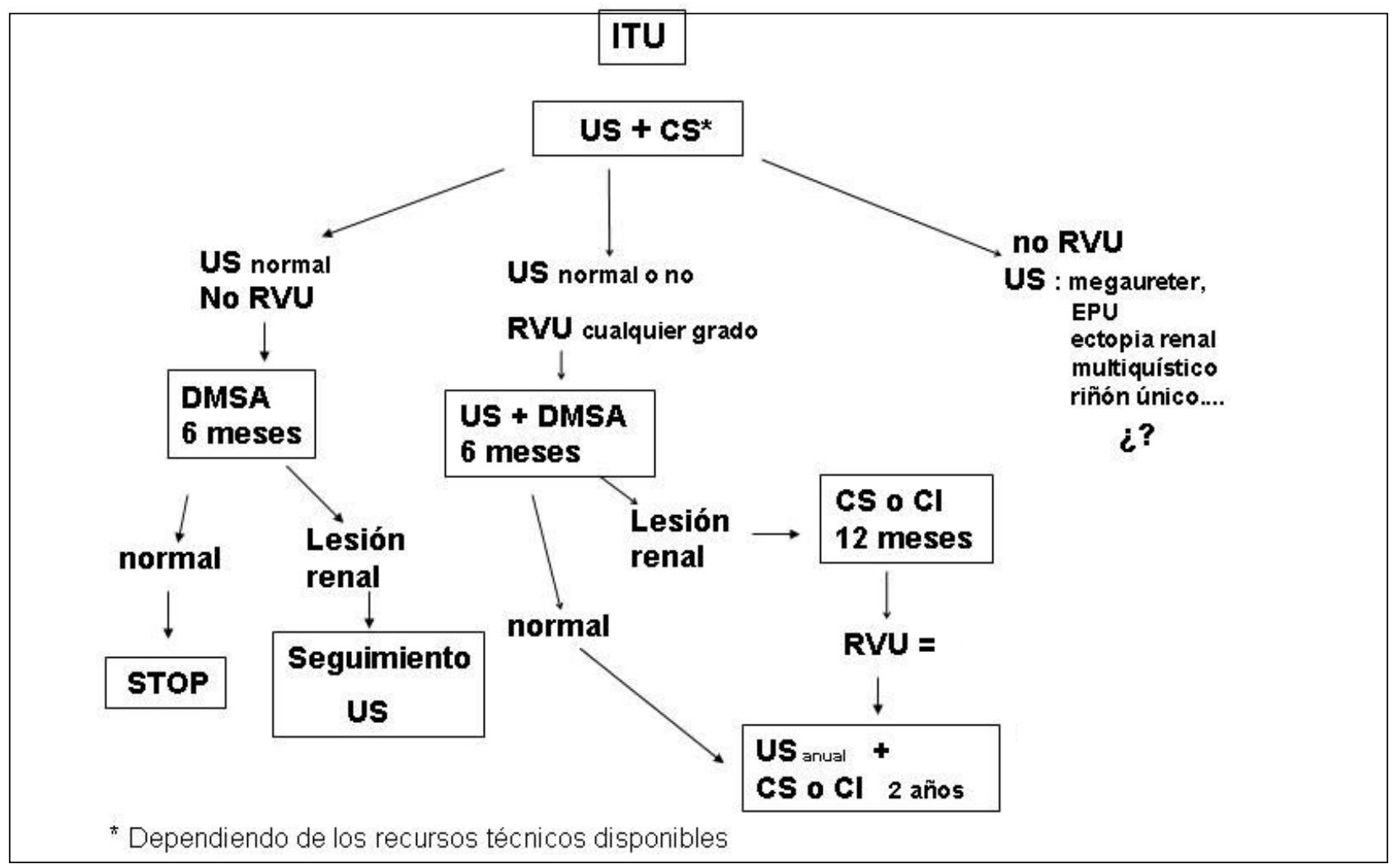




\section{BIBLIOGRAFÍA y LECTURAS RECOMENDADAS (*lectura de interés $y$ ** lectura fundamental)}

1. GARIN, E.H.; CAMPOS, A.; HOMSY, Y.: "Primary vesicoureteral reflux: Review of current concepts". Pediatr. Nephrol., 12: 249, 1998.

**2. FERNANDEZ, J.M.; MALAGA, S.: “¿Es posible cambiar el paradigma reflujocéntrico?”. Evid. Perdiatr., 2: 17, 2006.

*3. STEFANIDIS, C.J.; SIOMOU, E.: "Imaging strategies for vesicoureteral reflux diagnosis". Pediatr. Nephrol., 22: 937, 2007.

4. RICCABONA, M.; FRITZ, G.; RING, E.: "Potential applications of three-dimensional ultrasound in the pediatric urinary tract: Pictorial demonstration based on preliminary results". Eur. Radiol., 13: 2680, 2003.

5. RICCABONA, M.; RING, E.; HABERLIK, A.: "Threedimensional ultrasound(3DUS) based virtual cystoscopy in children: Feasibility and preliminary results". Pediatr. Radiol., 36: 74, 2006.

*6. LEBOWITZ, R.L.; OLBING, H.; PARKKULAINEN, K.V. y cols.: "International system of radiographic grading of vesicoureteral reflux". Pediatr. Radiol., 15: 105, 1985.

7. O'HARA, S.M.: "Vesicoureteral reflux: Latest option for evaluation in children". Radiology, 221: 283, 2001.

*8. BERROCAL, T.; GAYA, F.; ARJONILLA, A. y cols.: "Vesicouretral reflux: Diagnosis and grading with ecoenhanced cystosonography versus voiding cystouretrography”. Radiology, 221: 359, 2001.

9. KOFF, S.A.; WAGNER, T.T.; JAYANTI, V.R.: "The relationship among dysfunctional elimination syndromes, primary vesicoureteral reflux and urinay tract infections in children". J. Urol., 160: 1019, 2001.

10. ASCENTI, G.; ZIMBARO, G.; MAZZIOTTI, S. y cols.: "Vesicoureteral reflux: comparison between uronosonography and radionuclide cystography". Pediatric Nephrol., 18: 768, 2003.

11. MANDELL, G.A.; EGGLI, D.F.; GILDAY, D.L.: "Procedure guideline for radionuclide cystography in children". J. Nucl. Med., 38: 1650, 1997.

12. GORDON, I.; COLARINHA, P.; FETTICH, J. y cols.: "Guidelines for indirect radionuclide cystography". Eur. J. Nucl. Med., 28: 16, 2001.

13. BENADOR, D.; BENADOR, N.; SLOMAN, D.O. y cols.: "Cortical scintigraphy in the evaluation of parenchymal changes in children with pyelonephritis". J. Pediatr., 124: 17, 1994.

14. BIGGI, A.; DARDANELLI, L.; CUSSINO, P. y cols.: "Prognostic value of the acute DMSA scan in children with first urinary tract infection". Pediatr. Nephrol., 16: 800, 2001.

15. NOLTE-ERNSTING, C.C.; ADAM, G.B.; GUNTHER, R.W.: "MR Urography: Examination techniquesand clinical applications". Eur. Radiol., 11: 355, 2001.

16. AVNI, E.F.; BALI, M.A.; REGNAULT, M.,y cols.: "MR urography in children". Eur. Radiol., 43: 154, 2002.

17. ROHRSCHNEIDER, W.K.; HAUFE, S.; CLORIUS, J.H. y cols.: "MR to assess renal function in children". Eur. Radiol., 13: 1033, 2003

18. MOURIQUAND, P.; WHITTEN, M.; PRACOS, J.P.:
"Pathophysiology, diagnosis and management of prenatal upper tract dilatation". Prenat. Diagn., 21: 942, 2001.

19. UPADHYAY, J.; Mc LORIE, G.A.; BOLDUC, S. y cols.: "Natural history of neonatal reflux associated with prenatal hydronephrosis: Long-term results of a prospective study". J. Urol., 169: 1837, 2003.

20. ISMAILI, K.; HALL, M.; PIEPSZ, A. y cols.: "Primary vesicoureteral reflux detected in neonates with a history of fetal renal pelvis dilatation: A prospective clinical and imaging study". J. Pediatr., 148: 222, 2006.

*21. RICCABONA, M.; FOTTER, R.: "Radiographic studies in children with kidney disorders: What to do and when". Hogg R(ed) Kidney disorders in children and adolescents: A global perspective of clinical practice. Taylor \&Francis group, London-New York, pp. 15-33, 2006.

22. ZERIN, J.M.; RITCHEY, M.L.; CHANG, A.C.: "Incidental vesicoureteral reflux in neonates with antenatally detected hydronephrosis and other renal anomalities". Radiology, 187: 157, 1993.

23. YEUNG, C.K.; GODLEY, M.L.; DHILLON, H.K. y cols.: "The characteristics of primary reflux in male and female infants with prenatal hydronephrosis". Br. J. Urol., 80: 319, 1997.

24. SILLEN, U.: "Vesicoureteral reflux in infants". Pediatr. Nephrol., 13: 355, 1999.

25. FARHAT, M.; Mc LORIE, G.; GEARY, D. y cols.: "The natural history of neonatal vesicoureteral reflux associated with antenatal hydronephrosis". J. Urol., 164: 1057, 2000.

26. WENNESTRÖM, M.; HANSSON, S.; JODAL, U. y cols.: "Primary and adquired renal scarring in boys and girls with urinary tract infection". J. Pediatr. 136: 30, 2000.

27. MOORTHY, I.; EASLY, M.; McHugh, K.,y cols.: "The presence of vesicoureteral reflux does not identify a population at risk for renal scarring following a first urinary tract infection". Arch. Dis. Child., 90: 733, 2005.

28. WENNESTRÖM, M.; HANSSON, S.; JODAL, U. y cols.: "Primary and adquired renal scarring in boys and girls with urinary tract infection". J. Pediatr. 136: 30, 2000.

29. LEROY, S.; MARC, R.; ADAMSBAUM, C. y cols.: "Prediction of vesicoureteral reflux after a first febrile urinary tract infection in children: Validation of a clinical decision rule". Arch. Dis. Child., 91: 241, 2006.

30. HOBERMAN, A.; CHARRON, M.; HICKEY, R.W. y cols.: "Imaging studies after a first febrile urinary tract infection in young children". N. Engl. J. Med. 348:195, 2003.

31. ZAMMIR, G.; SAKNAN, W.; HOROWITZ, Y. y cols.: "Urinary tract infection: Is there a need for routine renal ultrasonography?”. Arch. Dis. Child., 89: 446, 2004.

32. GIORGI, L.J. Jr.; BRATSLAVSKY, G.; KOGAN, B.A.: "Febrile urinary tract infections in infants: renal ultrasound remains necessary". J. Urol., 173: 568, 2005.

33. BERROCAL, T.; GAYA, F.; ARJONILLA, A.: "Vesocoureteral reflux: Can the urethra be adequately assessed by using contrast-enhanced voiding US of the bladder?”. Radiology, 234: 235, 2005.

*34. RICCABONA, M. y FOTTER, R.: "Reorientation and future trends in paediatric uroradiology". Ped. Radiol. 34:295, 2004. 